\title{
Virus Load and Incidence Olfactory, Gustatory, Respiratory, Gastrointestinal Disorders in COVID-19 Patients: A Retrospective Cohort Study
}

\author{
Mohammad Hosein Taziki Balajelini ${ }^{1}$, Abdolhalim Rajabi ${ }^{1}$, Masoud Mohammadi ${ }^{1}$, Hadi \\ Razavi Nikoo ${ }^{1}$, Alijan Tabarraei ${ }^{1}$, Mohsen Mansouri ${ }^{1}$, and Seyed Mehran Hosseini ${ }^{1}$ \\ ${ }^{1}$ Golestan University of Medical Sciences
}

March 21, 2021

\begin{abstract}
Objectives: This study investigated the relationship between viral load and the incidence and recovery of olfactory and gustatory dysfunction (OD and GD), incidence of respiratory and gastrointestinal symptoms in COVID-19 patients. Design: A Retrospective Cohort Study. Setting and Participants: In total 599 outpatients' cases polymerase chain reaction (PCR)-confirmed COVID-19-positive patients in Golestan province were included in the study. Main Outcome Measures: The incidence of OD, GD, their severity and the time of recovery was determined. The association of these variables with cycle threshold (CT) values of SARS-CoV-2 polymerase chain reaction was assessed. Results: The mean age of patients was $38.27 \pm 13.62$ years. The incidence of general symptoms included myalgia $70.1 \%$, headache $51.8 \%$, fever $47.7 \%$, and dyspnea $21.4 \%$. $41.9 \%$ of patients had gastrointestinal symptoms, including abdominal pain $26.5 \%$, diarrhea $25.2 \%$, nausea $20.5 \%$, and vomiting $12.9 \%$. $12.2 \%$ of patients had comorbidity. The trimester recovery rates of OD and GD were $93.94 \%$ and $94.74 \%$, respectively. The mean recovery time of OD and GD was $14.56 \pm 13.37$ and $13.8 \pm 3.77$ days, respectively. The mean CT value in all patients was $27.45 \pm 4.55$. There were significant associations between $\mathrm{CT}$ value with headache $(\mathrm{P}=0.04), \mathrm{GD}(\mathrm{P}=0.002)$ and $\mathrm{OD}(\mathrm{P}=0.001)$. Conclusions: The intensity and the recovery of OD and GD in Covid-19 patients may be affected by initial viral load. Unlike to respiratory and gastrointestinal symptoms, the OD and GD were associated with lower viral load. Therefore, it may be recommended to use these clinical symptoms as an indicator in the initial screening of patients during pandemics.
\end{abstract}

\section{Hosted file}

Main Doc Rev.pdf available at https://authorea.com/users/403018/articles/514687-virus-loadand-incidence-olfactory-gustatory-respiratory-gastrointestinal-disorders-in-covid-19patients-a-retrospective-cohort-study 


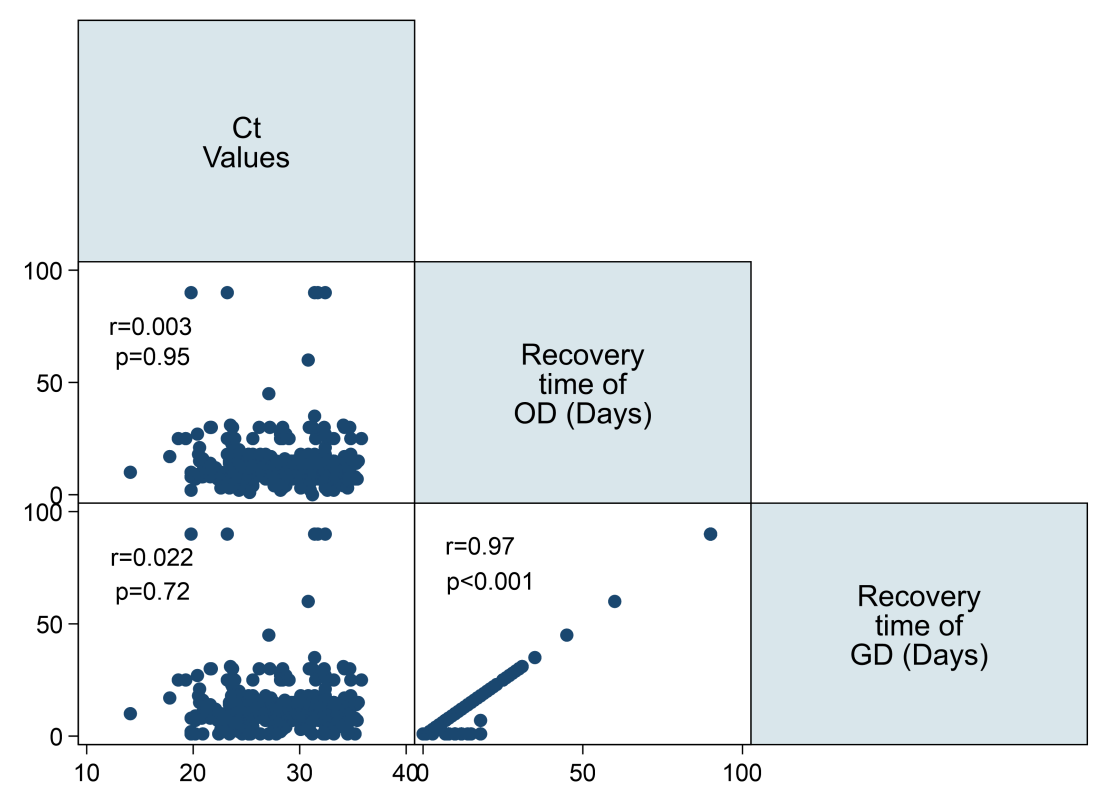

